Article

\title{
Innovations in Sustainable Groundwater and Salinity Management in California's San Joaquin Valley
}

\author{
Nigel W. T. Quinn ${ }^{1,2, *(1)}$ and James D. Oster ${ }^{3}(\mathbb{C}$ \\ 1 HEADS, Lawrence Berkeley National Laboratory, Berkeley, CA 94720, USA \\ 2 School of Engineering, University of California, Merced, CA 95353, USA \\ 3 Department of Environmental Sciences, University of California, Riverside (Emeritus), CA 92521, USA; \\ james.oster@ucr.edu \\ * Correspondence: nwquinn@lbl.gov or nquinn@ucmerced.edu; Tel.: +1-510-612-8802
}

Citation: Quinn, N.W.T.; Oster, J.D. Innovations in Sustainable Groundwater and Salinity Management in California's San Joaquin Valley. Sustainability 2021, 13, 6658. https://doi.org/10.3390/ su13126658

Academic Editor:

Ioannis Panagopoulos

Received: 20 May 2021

Accepted: 9 June 2021

Published: 11 June 2021

Publisher's Note: MDPI stays neutral with regard to jurisdictional claims in published maps and institutional affiliations.

Copyright: (c) 2021 by the authors. Licensee MDPI, Basel, Switzerland. This article is an open access article distributed under the terms and conditions of the Creative Commons Attribution (CC BY) license (https:// creativecommons.org/licenses/by/ $4.0 /)$.

\begin{abstract}
The Sustainable Groundwater Management Act (SGMA) of 2014 and the Central Valley Salinity Alternatives for Long-Term Sustainability (CVSALTS) initiative were conceived to reverse years of inaction on the over-pumping of groundwater and salination of rivers that both threaten agricultural sustainability in the State of California. These largely stakeholder-led, innovative policy actions were supported by modern tools of remote sensing and Geographic Information System technology that allowed stakeholders to make adjustments to existing resource management and jurisdictional boundaries to form policy-mandated Groundwater Sustainability Agencies (GSAs) and Salinity Management Areas (SMAs) to address future management responsibilities. Additional resources mobilized by the California Department of Water Resources (CDWR) and other water resource and water quality management agencies have been effective in encouraging the use of spreadsheet accounting and numerical simulation models to develop robust and coherent quantitative understanding of the current state and likely problems that will be encountered to achieve resource sustainability. This activity has revealed flaws and inconsistencies in the conceptual models underpinning this activity. Two case studies are described that illustrate the disparity in the challenges faced by GSAs in subregions charged with developing consensus-based Groundwater Sustainability Plans (GSPs). These case studies also illustrate the unique aspect of SGMA: that alongside mandates and guidelines being imposed statewide, local leadership and advocacy can play an important role in achieving long-term SGMA and CVSALTS goals.
\end{abstract}

Keywords: groundwater sustainability planning; salinity management; SGMA; CVSALTS; stakeholder participation; numerical simulation modeling; State of California; land subsidence; water quality

\section{Introduction}

The Sustainable Groundwater Management Act (SGMA) and Central Valley Salinity Alternatives for Long-Term Sustainability (CVSALTS) initiatives have fundamentally changed future groundwater management in California [1,2]. Both embrace a holistic conceptual understanding of the resource and the interconnectedness of this resource with other vulnerable resources and the citizenry of the state. This shift in perspective also creates a need for a new suite of decision support tools to help stakeholders make cost effective, efficient, equitable, transparent and socially responsible decisions in the future.

This paper describes the genesis of these two initiatives and reviews recent advances as California water agencies and stakeholders work together to develop the institutional capability to implement these policies. Although this paper deals with groundwater and salinity management issues in California, one of the major lessons we hope the international readership draws from the analysis we present is that good policy, properly implemented and adequately resourced, can move a region from having one of the worst water and salinity management records to a path to having one of the best. 
The Sustainable Groundwater Management Act (SGMA), which affects everyone in California, was signed into law by Governor Brown of California on Sept 14, 2014 [1]. The objective of SGMA is to ensure long-term sustainable yield of groundwater within 20 years that accounts the following undesirable results: (a) surface water depletion resulting from groundwater use near irrigation canals, (b) reduction in groundwater storage, (c) degradation of water quality, (d) seawater intrusion, (e) land subsidence, and (f) lowering groundwater levels. Between 2014 and 2017, the Department of Water Resources identified 515 alluvial basins and prioritized the severity of the groundwater overdraft as high, medium or low [3]. Those prioritized as high and medium and critically overdrafted were obligated to submit groundwater management sustainability plans by January 2020 [1]. The remainder of the areas, not covered in this preliminary round, will have until January 2022 to file their management plans.

Local control of groundwater is a unique aspect of SGMA. The development of management plans to assure a sustainable groundwater yield is performed by the Groundwater Sustainable Agency (GSA) formed for each subbasin. The structure of each GSA consists of a Board of Directors whose membership consists of people from county governments, water districts and stakeholders. These boards and constitutive committees include a Technical Advisory Committee (engineers, geologists, water managers), a Rural Advisory Committee consisting of officials from rural public water systems, and a Stakeholder Committee. The interests at stake include: 1 . agriculture and domestic holders of overlying groundwater right, 2. public water systems, 3. local land use planning agencies, 4. environmental users of groundwater, 5 . holders of surface water rights, 6 . native American tribes, and 7. disadvantaged consumers that include those served by domestic wells or small community water systems. The powers of a GSA include the registration, metering, monitoring, reporting, and regulation of all groundwater wells in the subbasin; the purchase of surface water replenishment; the adoption of rules, regulations, ordinances, and enforcement actions; and the imposition of administrative fees and assessment [1]. The development of a water budget for current and projected future conditions to 2070, to include the impacts of climate change, is the first step in developing a management plan $[4,5]$.

\section{Genesis of SGMA and CVSALTS}

The legal history of water development in California dates back to 1887 [6] with the passage of the Wright Act, followed by federal and state bills that provided funds to develop the dams to collect and store water and canal systems to convey the stored surface water to crop land where it was used for irrigation. While the majority of these laws targeted water rights and water allocation, fewer dealt with water quality and the groundwater resource was largely ignored. The recognition of groundwater subsidence due to overpumping of groundwater in the San Joaquin Valley [7] between 1925 through the 1950s led to the importation of surface water from the pump stations located in the Sacramento-San Joaquin River Delta as a means of reversing damage to water conveyance infrastructure. However, this solution, applauded at the time, initiated an increase in soil salinization in the San Joaquin Basin and necessitated the introduction of environmental legislationthe Porter-Cologne Water Quality Control Act in 1969, and the California Environmental Quality Act in 1970 — that recognized the San Joaquin River as an impaired waterbody [8,9]. This designation resulted in federal action by the US Environmental Protection Agency and the imposition of a Total Maximum Daily Load to sustain stakeholder beneficial uses of the San Joaquin River [10].

This conservative regulatory approach for water quality management led to the development of an alternative real-time stakeholder-involved real-time water quality management approach that relied upon 30-day running average salinity concentration objectives at compliance monitoring locations along the mainstem of the river and a commitment to real-time monitoring, stakeholder cooperation and coordination and investment in the cyberinfrastructure for real-time salinity forecasting [11]. The innovative regulatory approach undertaken for the San Joaquin Basin has been extended to the entire Central 
Valley of California through a more recent stakeholder-led salinity management initiative known as CVSALTS [2] that is developing strategies for salt management to maintain and sustain the beneficial use of water resources. The CVSALTS initiative is financed by entirely stakeholder voluntary contributions in recognition of the greater flexibility offered by local control and management of salinity in surface waters of the state [2].

Surface water and groundwater have long been managed by the federal and state water agencies as two entirely distinct and separate systems despite knowledge and evidence of their interaction and inter-relationship. Despite this conceptual and institutional oversight, the importation of water supply from the Sacramento-San Joaquin Delta to offset widespread land subsidence issues caused by groundwater over-pumping had successfully reversed a regional decline in groundwater storage until 1990. The severe drought in 1977 and the steady increase in urban demand did not impact the recovery of the groundwater system. Policy initiatives in 1991/1992 listed winter-run salmon in the San Joaquin River and the delta smelt (a small endemic fish that inhabits the freshwater-saltwater mixing zone in the delta) estuary. These policies changed the reservoir flow release patterns and restricted water export through the federal and state pumping plants during certain times of the year where the smelt were in danger of entrainment. In 1992, the Central Valley Improvement Act brought about a significant reallocation of developed water supply-800,000 acre-ft (987 million $\left.\mathrm{m}^{3}\right)$-in support of environmental resource restoration including seasonally managed wetlands. Although, at the time, these initiatives to redress the imbalance between agricultural municipal and environmental beneficial uses were popular within the State of California, the long-term consequences of these actions are now being realized. Agricultural customers of federal water supply located south of the delta received a 100\% water supply allocation in 1979_today, agricultural customer allocations are between $40 \%$ and $50 \%$ of the federal supply contracts. Prior to 1990 water shortages during severe drought could be alleviated by voluntary water transfers between agriculture and other urban, industrial and environmental beneficial uses. Water reallocations, delta pumping restrictions and land use changes to permamnent crops like vineyards and orchards has reduced the resiliency of the California water system.

California's passage of the California Sustainable Groundwater Management Act (SGMA) in 2014 "is an example of how what occurs "overnight" can be a century in the making" [1,12]. California frequently now leads the nation in progressive legislation, as evidenced by sections of the state's Porter-Cologne Water Quality Control Act being used as an exemplar for the Federal Clean Water Act. In 2006, the California legislature, under a Republican administration, took action on climate change-the first state to do so. Progressive as this action was, California remained the only state in the nation that had not adopted statewide mandates for groundwater regulation. Prior to the passage of SGMA, groundwater use was unregulated. Irrigators could augment existing surface water supply by drilling wells and accessing available groundwater. Groundwater is the sole source of irrigation water supply in some areas of the state, and is a backup water source in others, during prolonged droughts. The general perception among such landowners, called "overliers", was that they had to right to extract as much water as they wanted [12]. See (a) below. The Supreme Court of California did not agree when, in 1903, it decreed that landowners share equally. See (b) below.

a. The issue in a case known as Katz v. Walkinshaw [12] was the assertion " that each landowner owns absolutely the percolating waters in his hand, with the right to extract, sell and dispose of them as he chooses, regardless of the results to his neighbor, is part of the common law, and as such has been adopted in this State as the law of the land..."

b. The wording of the ruling by the presiding judge of the Supreme Court of California was as follows [12]: "Disputes between overlying landowners, concerning water for use on the land to which they have an equal right, in cases where the supply is insufficient for all, are to be settled by giving to each a fair and just proportion." 
Between 1903 and 2014, there were several instances where there were opportunities to establish a statewide system to regulate groundwater use.

Between 1903 and 2014, the courts of California and the California legislature enacted policy that gave precedent to the establishment of a statewide system to regulate groundwater. In 1914, the enactment of the Water Commission Act created the agency that has become today's State Water Resources Control Board. The first amendment of this act clarified that it only applied to surface water-it established a permit system for the appropriation of surface water rights. This was followed by several bills that mandated a series of groundwater investigations (Leahy 2016). In 1949, the adjudication of a groundwater basin in southern California, used by the cities of Pasadena and Alhamba, played a key role in establishing how to manage and allocate groundwater within a basin as well as a definition of safe yield: "the maximum quantity of water that can be continuously withdrawn from a groundwater basin without adverse effect" [13]. Legislation passed in 1953-54 set up the legal authority for a pump tax, the proceeds of which would only be used to acquire water for the replenishment of district groundwater supplies [12]. Frank Durkee, the State Director of Public Works at that time, wrote to Governor Earl Warren, urging the signature of the bill, stating the "proposal to levy assessments upon production of groundwater for the purpose of replenishing an overdraft on groundwater basins is a new principle in this State" [12,13].

The extended drought that began in 2007 and lasted through 2013 stimulated legislative actions dealing with water policy [12]. The future of irrigation and available drinking water was at stake. During this drought period, the availability of surface water for irrigation was severely limited and groundwater became a major source of irrigation water. Groundwater levels declined to historic lows, irrigation and drinking water wells went dry, land subsidence cracked and misaligned irrigation canals, and there was permanent depletion of storage space in the aquifers that underly California. The capability and capacity of canals to deliver surface water was reduced, as was the amount of groundwater available to buffer against future droughts. Continued use of groundwater greater than the rate of recharge was hastening the time when major reductions in irrigation would occur.

The conception of SGMA was a departure from previous groundwater management policies that relied on an understanding of safe yield and sustainable use of the resource from an extraction perspective. SGMA, instead, requires that attention be paid to the potential undesirable impacts of groundwater pumping, including chronic lowering of groundwater levels, reduction in groundwater storage, land subsidence, water quality degradation, and depletions of interconnected surface water systems (Figure 1) [14]. Seawater intrusion was the sixth undesirable result that is not applicable to groundwater basins in the San Joaquin Valley. 


\section{Sustainable Management Criteria}

\section{$\S$ 354.24. Sustainability Goal}

- A single sustainability goal for the basin

- Achieved within 20 years of GSP implementation

- Maintained without causing undesirable results
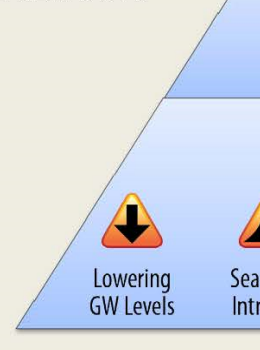

DRAFT GSP Emergency Regulations - Subject to Revision

Figure 1. Sustainable management criteria applicable to Groundwater Sustainability Plan (GSP) development [1]—https://acwi.gov/swrr/p\&p_library /May_2018/19_altare_sma_smc_swrr_may_ 2018.pdf (Accessed on 8 May 2021).

\section{Implementing CVSALTS and SGMA Policies}

The CVSALTS and SGMA initiatives both followed a Little Hoover Commission review of the CALFED Bay-Delta Program (2005) that recommended that all future water policy initiatives have direct stakeholder involvement [15]. The Little Hoover Commission is an independent California State oversight agency created in 1962 that investigates state government operations and promotes efficiency, economy and improved service through reports, recommendations and legislative proposals. The CALFED Bay-Delta Program [8] was formed as a joint state-federal entity in 1994 to coordinate water management activities primarily in the Sacramento-San Joaquin River Delta and develop appropriate science-based delta water quality standards. State and federal government agencies and stakeholders representing many local water agencies and environmental organizations signed an agreement on water quality titled, "Principles for Agreement on Bay-Delta Standards between the State of California and the Federal Government," commonly referred to as the Bay-Delta Accord [8]. The accord was supposed to mark a critical milestone in California water history, resolving conflict and leading to greater future collaboration and joint planning activities.

Despite a considerable record of accomplishment, the commission determined that: (a) the current CALFED governance structure did not efficiently and meaningfully involve the broader public, provide the necessary transparency in the decision-making process or assertively resolve conflicts; and (b) the State of California should, in future, be obligated to provide more meaningful opportunities for the public and stakeholders to participate in the CALFED planning process to raise awareness, increase transparency, reduce conflicts and provide accountability [15]. The commission recognized an overall lack of public access to critical information for making planning decisions and the lack of an effective means of communication to ensure that the public was being heard [15].

The lessons drawn from the CALFED review and directed at the CVSALTS and SGMA initiatives were built upon the premise that conflict over water policy was more likely to be resolved locally and without resort to costly, long-term litigation when priority 
was given to local involvement at program onset. In the case of both CVSALTS and SGMA, the disaggregation of the river basin into distinct management zones (CVSALTS) or Groundwater Sustainability Agencies (SGMA) gave stakeholders significant control of the boundary setting for these areas and fostered the development of a coalition of interested parties from within the stakeholder group. The California Department of Water Resources provided initial maps of groundwater basins previously established for the reporting of groundwater conditions that provided an initial basin for GSA formulation and jurisdictional boundary delineation $[16,17]$.

Under SGMA, the GSA was recognized as the primary entity responsible for achieving groundwater sustainability. The GSAs in basins ranked high- and medium-priority $[16,17]$ were charged with early development and implementation of groundwater Sustainability Plans (GSPs) by January 2020. The formulation of the GSPs had to consider the interests of all beneficial uses and users of groundwater within their jurisdictions. The rationale for this prioritization was the recognition that the severity of the problems faced in these basins would require more time to resolve. The policy analysts responsible for the design of the SGMA allowed basins to adopt one or multiple GSPs but made sure in these instances that coordination agreements be designed and enacted between the GSAs named under each GSP. The SGMA legislation was expansive, providing GSAs with new authorities and decision support tools to manage the groundwater resource with the goal of meeting the primary objectives of the GSP. These new authorities included a mandate to conduct investigations, measure pumpage and impose limits on extraction, perform analysis to estimate the sustainable groundwater yield of each basin, recover the cost of groundwater management activities, and enforce the goals of the GSP filed with the California Department of Water Resources (CDWR) [18]. These authorities and their ability to survive legal challenges will be key to the long-term success of the program. In the interim, state planning and enforcement laws may need to be updated and amended to provide maximum flexibility and support to stakeholders encouraging the high level of cooperation and coordination necessary to develop equitable and long-lasting management solutions.

Osterling [19] suggested that there is a need to more clearly account for the sources of aquifer recharge to better assign groundwater sustainable yield. He posed that analysts recognize three sources of water: native, foreign and salvage. Native sources are those available to everyone, including rain, canal seepage from GSA sources, surface return flows from groundwater pumped within a GSA, inflow from watersheds above the valley floor often drained by ephemeral streams, and infiltration diverted from streams into subsiding subareas within the basin [19]. Foreign sources can include canal seepage from imported sources, subsurface drainage from adjacent basins or subsiding subareas and irrigation return flows from imported sources. Salvaged sources can include canal seepage from water supply conveyances to the GSA service areas and return flows from storm water. In California, all surface water sources are appropriated in that all water supply belongs to some entity, including seepage losses from appropriated water supplies. Water budgets developed by water agencies and other planning entities rarely recognize these distinctions.

Some entities [4] have criticized some of the regulatory deficiencies in the initial formulation of the SGMA conceptual framework, in particular, the boundaries of the groundwater basins based on CDWR Bulletin 118 that are used to define each GSA jurisdictional area. The authors note that by focusing only on alluvial basins and ignoring hard rock and volcanic aquifers and not defining the lower boundary of each groundwater basin (allowing local agencies to exclude lower lying brackish groundwater), this potentially allows use of these resources unconstrained by SGMA regulations [4]. The same authors note that approximately 40 percent of all wells exist in fractured hard rock and volcanic formations, which are relied upon for drinking water by rural communities and forest and aquatic ecosystems and that can provide recharge to alluvial groundwater aquifers downslope in the alluvial valley floor. Discounting these resources outside the SGMA jurisdictional boundaries can significantly underestimate the volume of the usable groundwater system. Similarly, with SGMA focusing initially on alluvial basins in medium- or high-priority 
groundwater basins, groundwater pumping in lower priority basins can still lead to undesirable results over time, such as the depletion of streamflow. Failure to recognize the interconnectedness of the surface and groundwater systems could have unanticipated secondary impacts.

The availability and promotion of analytical tools and accessible numerical models was recognized early in the SGMA process as being key to GSA formation and successful GSP development and implementation. A technical committee was formed to help develop guidelines for the use of these tools. Ideally, the models used would be in the public domain, providing transparency and the ability to replicate results of simulations of future scenario projections on the relevant sustainability indexes. The CDWR organized workshops to encourage use of their Central Valley regional C2VSIM model [20,21]. The model had been formulated at two levels of discretization to facilitate choice in the most appropriate level of hydrologic detail for use by GSAs [21], while recognizing that this is dictated by the fidelity of available data. A common template was developed by CDWR for the formulation of annual water balance spreadsheets in lieu of more complex numerical simulation models. This option was chosen by many GSAs who had not invested in groundwater simulation models as part of their groundwater resource management activities. Those GSAs that did have established models were permitted to continue their use and to further develop these models for the formulation of management scenarios and assessment of these scenarios relative to the implementation of the GSP. Data sets and output from these models were required to be accessible to analysts at CDWR and other interested stakeholders.

One important analysis made possible by these analytical tools is the assessment of groundwater recharge directly from precipitation, irrigation or surface water banking activities or indirectly through aquifer-stream inflow or deep well injection [4]. These tools can also help establish pumping setbacks from streams to protect surface water allocations of water and riparian habitats in instances where hydraulic gradients toward the rivers are reversed and streams are losing water to the local groundwater aquifer.

\section{Governance Issues-Alternatives Methods for Organizing a GSA}

Following the mandates of the Little Hoover Commission [15], the SGMA architects have striven to aid and abet stakeholder jurisdiction acting through the GSA over policy related to future groundwater management, encouraging innovation while making sure that the process adheres to state law. The GSA would still need to coordinate with local land use and water agencies within each basin. Where no like entity exists, a new entity would need to be formed either expanding the jurisdiction of an existing water district or forming a new entity as a Joint Powers Agency or enacting legislation that allows the recognition of a special administrative district. There are significant challenges in managing multi-use, multi-jurisdictional groundwater basins under a single entity, especially when these involve additional cost sharing and reporting obligations when hitherto these did not exist.

An alternative governance model might call for more distributed jurisdictional authority and the creation of multiple GSAs with collective jurisdiction over the whole groundwater basin with police power for the planning, monitoring and implementation of a GSP established within each GSA [4]. This distributed model has been adopted by stakeholders in the San Joaquin Valley. This governance structure allows existing local agencies to retain existing authorities and assume new authorities for groundwater management in their existing service area and allow for more localized control. However, this option requires significant coordination among all the entities on an array of management issues because each GSA would need to adhere to constraints imposed on the basin as a whole.

A third option is a hybrid approach that centralizes certain important authorities and practices while distributing other less important functions among multiple entities [4]. For instance, general tasks that relate to groundwater management planning activities, GSA coordination and public outreach could be conducted within a single centralized GSA, whereas groundwater management and pumping enforcement tasks would be split 
among responsible GSAs. This governance model is more complex in its architecture but ultimately should offer a high degree of flexibility and autonomy in those areas that may be politically problematic. The development of viable groundwater management solutions may require novel and previously untried strategies - these can be fostered in an environment where flexible governance, better tools for resource management and the availability of dedicated expertise can be mustered to achieve SGMA objectives. Developing a high fidelity understanding of the dynamics of the groundwater system can take time and is best achieved through an adaptive management approach where models are calibrated and validated as a means of archiving this knowledge [22].

\subsection{GSA Formation and Planning under SGMA}

The design of an institutional framework for SGMA implementation was achieved with the decision to require all entities, initially those in the medium- and high-priority basins in the Central Valley, to develop Groundwater Sustainability Agencies (GSAs) [1,4,5]. These institutions would provide the oversight and governance needed to achieve groundwater sustainability goals. The first decision that stakeholders needed to make was to work out the geographic boundaries of these areas in accordance with stakeholder preferences and priorities (Figure 2). Nine factors were suggested for consideration in the formation of GSAs $[5,23]$. These factors are scale, human capacity, funding, authority, independence, participation, representation, accountability, and transparency [23]. The first five factors were those that directly affect the ability of a GSA to meet sustainability goals. The scale and jurisdictional boundaries of the GSA are critical not only for long-term financing of SGMA-related resource management activities but also for the coordination that might be needed if a large number of jurisdictions and resource boundaries were folded into a single GSA [23]. The CDWR developed a useful GIS-based resource (Figure 2) to assist in the process of negotiating these jurisdictional boundaries, facilitating the decision-making process but giving stakeholders ultimate responsibility for the outcome.

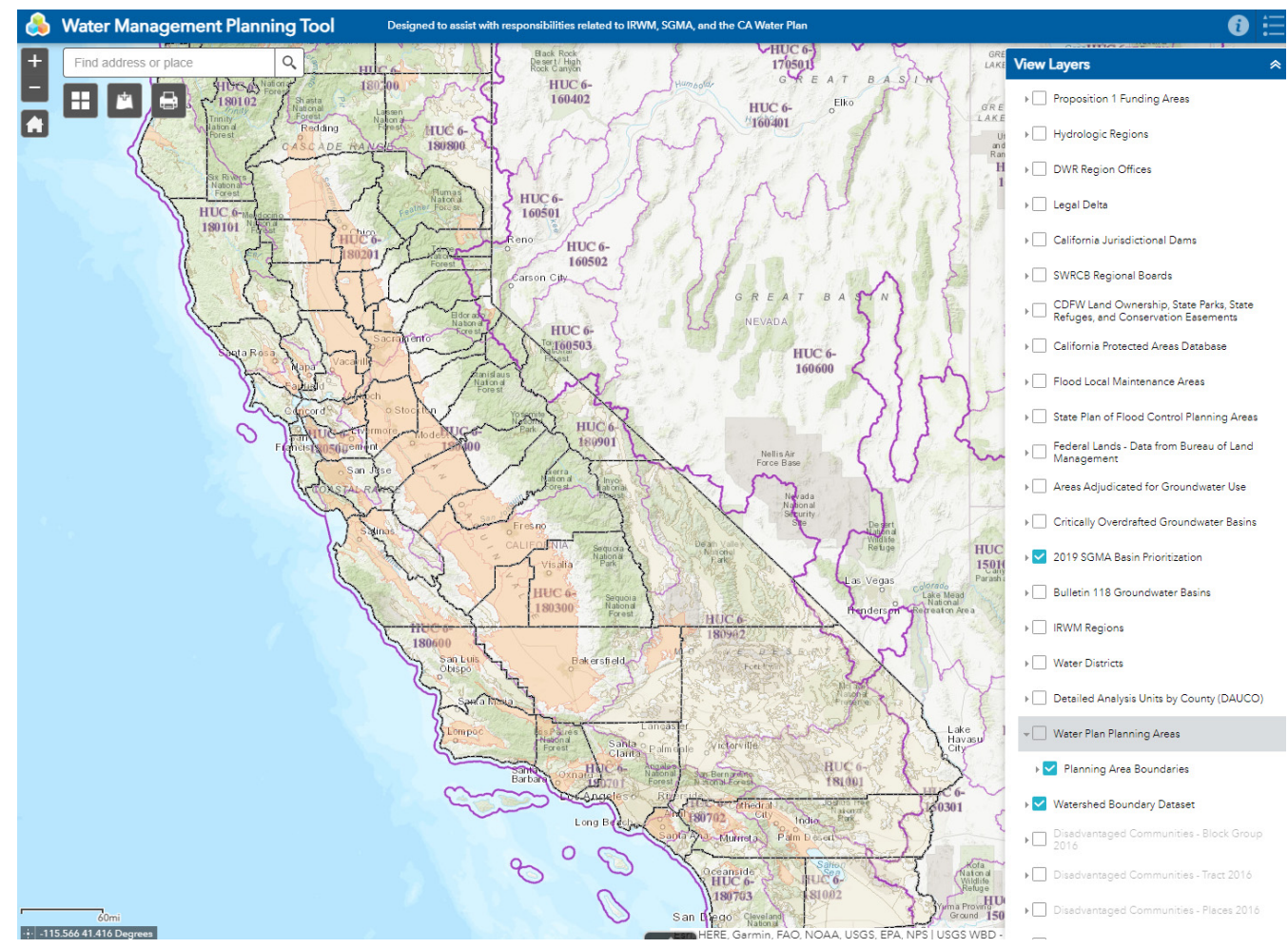

Figure 2. The GIS-based Water Management Planning Tool used for overlaying jurisdictional and hydrology-related maps to aid delineation of GSA boundaries, https:/ /sgma.water.ca.gov/portal/ \#intro (Accessed on 8 May 2021). 


\subsection{Decision Support for CVSALTS and SGMA Policy Implementation}

The water agencies responsible for the allocation and distribution of developed water supplies in the State of California-the USBR and CDWR-have traditionally focused their planning activities on water supply [24]. The decision tools developed and maintained by these agencies were used primarily to determine and justify water allocation decisions and coordinate water supply deliveries between the state and federal water projects [24]. These decision tools typically regarded groundwater as a residual that could be counted upon to fill the deficit between water needs and water supply.

Before 1992, when the Central Valley Improvement Act brought about a significant reallocation of developed water supply-800,000 acre-ft $\left(987\right.$ million $\left.\mathrm{m}^{3}\right)$, - the water needs in the state were dominated by agricultural water requirements to satisfy crop evapotranspiration losses. In 1990, an interagency initiative to develop a more comprehensive understanding of the Central Valley groundwater resource led to the development of the Central Valley Groundwater Simulation Model (CVGSM). The model simulated Central Valley hydrology from 1922 to 1980 and quantified the steady decline in groundwater levels in some parts of the valley and the concern of a diminished groundwater resource in these areas. Although the original CVGSM model has since spawned new improved variants such as DWR's C2VSIM model $[20,21]$ and the USGS Central Valley Hydrology Model (CVHM) [25-27], full integration with surface water allocation models such as the interagency California surface water allocation simulation model (CALSIM) has still not been achieved even after thirty intervening years of development. However, progress has been made in the recognition that groundwater is a finite and limited resource and that simplistic metrics such as safe yield are of limited utility in providing decision support to agency managers and impacted stakeholders.

Another persistent oversight by the water agencies and entities representing stakeholders has been the lack of commitment to developing decision tools for water quality management. The CVSALTS initiative [2] has taken the first steps compiling and analyzing groundwater monitoring data collected by the United State Geological Survey (USGS), CDWR, the US Environmental Protection Agency, researchers within the University of California system and local planning agencies to develop preliminary maps of salinity and nitrate contamination within the Central Valley [2]. One of the major constraints to the use of these data has been the lack of easy access and different protocols for data quality assessment across the entities responsible for data collection and reporting. Attempts to develop GIS-based, publicly accessible data web portals for groundwater data have been less successful than those developed for surface water quality data. This fact and the low priority status of this requirement can explain the lack of decision support capability for groundwater quality management. Likewise, the lack of water quality simulation capability in the groundwater and surface water simulation models such as C2VSIM and CVHM has significantly lagged improvements in the ability of these models to accurately track changes in water table elevations and groundwater storage [20,21,25-27]. This heightened concern with respect to groundwater quality and the need to coordinate activities between CVSALTS and SGMA led to a relatively recent change in prioritization by CVSALTS to develop implementation strategies for groundwater nitrate management as part of their Salinity and Nitrate Control Program. Management zones for salinity management and for providing relief to communities whose wells now register above the $10 \mathrm{mg} / \mathrm{L}$ public health concentration limit for nitrate pollution have been reconciled.

Land subsidence is one of the most potentially costly of the undesirable impacts of unsustainable groundwater pumping. It caused significant damage to water conveyance infrastructure in the period between 1925 and 1950 and that has reappeared in the past decade as a serious constraint to sustainable agricultural production in the San Joaquin and Tulare groundwater basins $[9,25,26,28]$. Differential subsidence can cause cracks in the concrete lining of conveyance structures, resulting in water leakage and costly repair combined with water supply disruption. Several earth-lined canals have had to be dredged and the levees raised in the Grasslands subarea of the San Joaquin River Basin 
at the cost of several million dollars to combat the loss of conveyance capacity [28] and the fact that road crossings now impede canal flow in numerous locations. Although current groundwater simulation models of the Central Valley C2VSIM and CVHM have the capability to simulate land subsidence due to over-pumping $[20,25,28]$, only the more recently completed version of the CVHM model (CVHM2) has been calibrated to perform realistic simulations of this phenomenon $[25,26]$. In fact, the new CVHM2 model, with a greater number of layers assigned to aquitard layers, the ability to separately simulate elastic and inelastic properties of these aquitards and the added capability of recognizing the delay as these layers dewater in response to imposed pumping-induced stresses, has demonstrated superior performance [25-27]. Associated USGS subsidence monitoring and modeling studies have dispelled a common assumption that has pervaded for more than 30 years, which is that the majority of land subsidence is related to inelastic compaction of the Corcoran Clay aquitard in the San Joaquin and Tulare basins [28]. Recent studies suggest that most non-recoverable subsidence occurs in the interbedded thinner aquitards that lie below the Corcoran Clay and that further hydro-compaction of the Corcoran Clay plays a much reduced role. Despite the improvements made in subsidence simulation in the newly released CVHM2 model, until this model is more widely distributed and utilized in SGMA-related planning and implementation studies, the analysis of subsidence impacts due to over-pumping within each GSA will be limited.

A potential future constraint on the performance of the CVHM2 model, even if more assiduously applied in GSA implementation planning, is the dearth of extensometer and other deep well monitoring data needed to rigorously calibrate and validate this routine within CVHM2. Extensometer monitoring is highly specialized and funding of this effort, primarily for the work of USGS scientists, has not been reliable and consistent in past years [28]. Other techniques such as InSAR (Interferometric Synthetic Aperture Radar), which makes high-density measurements by using radar signals from Earth-orbiting satellites to measure changes in land surface altitude, can accurately assess surface deformation over large areas. However, these surveys require highly trained personnel to perform the analysis and can be more costly to complete than a network of appropriately spaced extensometers. The utility of decision support tools such as CVHM2 is directly related to the availability of appropriate monitoring data to continually update and validate the model.

\subsection{Socioeconomic Secondary Impacts Addressed by SGMA and CVSALTS}

The ongoing COVID-19 pandemic has been especially hard on rural and disadvantaged communities with limited financial resources that often rely on shallow groundwater wells for domestic water supply. Nitrate pollution is endemic in rural California [13], and the recent lockdown and the loss of work income have exacerbated the vulnerability of these communities. These communities are also subjected to lowering of the local water table when water shortage encourages nearby agricultural operations to improve their water supply reliability through investment in deep wells. Although these wells are typically screened at great depth either immediately above or below the Corcoran Clay aquitard in the San Joaquin and Tulare Basins, aquifer stress induced by aggressive pumping will eventually dewater the overlying aquifer despite the flow retarding influence of interbedded discontinuous clay lenses between the soil surface and Corcoran Clay aquitard. Widespread water table lowering can impact an entire community that does not have the financial wherewithal to replace new wells or deepen expiring wells. CVSALTS has recently made groundwater well water quality assessment a priority relative to the longer- term salinity assessment and planning activities. This change in focus is directed at ensuring safe drinking water for compromised disadvantaged communities and promises to provide CVSALTS with a near-term success-a politically savvy strategy when reliant on stakeholder financial support. Recognition of the plight of disadvantaged communities has been increasingly recognized in bond-funded grant solicitations and requests for proposals over the past 5 years. These new grant initiatives have encouraged direct technical assistance efforts by outside consultants and newly formed entities who are being paid to 
work with these communities to develop comprehensive and cost-competitive drinking water enhancement programs.

The design and implementation of these grant programs have been somewhat ad hoc in the recent past, limited by a lack of decision support tool capability that might allow a multi-objective optimization analysis of investments in water supply infrastructure. Model objective functions can be reformulated to include community welfare and socioeconomic goals with other more traditional profit maximization and cost minimization goals that account for the undesirable impacts of groundwater pumping, described earlier. These undesirable impacts include the chronic lowering of groundwater levels, reduction in groundwater storage, land subsidence, water quality degradation, and depletions of interconnected surface water systems. Developing appropriate metrics and weighting systems that promote equity in resource availability and sharing while providing assurance of resource sustainability will require fresh thinking and new approaches to regional resource planning. This paper suggests some potential approaches.

\section{Case Studies of SGMA Planning and Early Implementation Actions}

The multitude of GSAs that represent the San Joaquin Valley of California are diverse in the problems they need to address and the resources they have available to overcome the many hydrologic, water quality and socioeconomic challenges associated with groundwater resource sustainability. This diversity is best illustrated by way of two preliminary case studies of GSAs located at either end of the San Joaquin Valley. Both regions, which are the subjects of these case studies, are impacted by five of the six previously described undesirable factors, although each has taken a different approach that has resulted in differential progress on the attainment of GSP goals to date. Given that the GSPs for both GSAs were only recently filed with the state (January, 2020) and that the GSP implementation period is 20 years, many of the more controversial decisions within each GSA have yet to be made and any resource management issues between GSAs are unlikely to have been fully identified. A more comprehensive case study and analysis of these GSAs will be the subject of a future paper. The following discussion describes the different challenges faced by the GSAs in their respective basis that has been gleaned from the GSPs filed with the state and offers some insight as to how the stakeholder-determined GSA boundaries topology might play into their ability to meet long-term SGMA objectives.

\subsection{Greater Kaweah Groundwater Sustainability Area (GWGSA)}

The Kaweah subbasin is a prime agricultural area of about 700 square miles $\left(1800 \mathrm{~km}^{2}\right)$ of the San Joaquin Valley of California [29]. The Kaweah subbasin is one of 127 subbasins in the state classified as critically overdrafted and subject to early implementation of sustainable pumping actions by December 2020. The Greater Kaweah GSA (GKGSA) jurisdictional area is approximately 340 square miles ( $50 \%$ of the Kaweah subbasin- $\left.884 \mathrm{~km}^{2}\right)$, comprising the East Kaweah GSA, the GKGSA and the Mid Kaweah GSA (Figure 3- [29]). Annual precipitation in the Central Valley of California diminishes from north to south and this region relies on surface water for the local Kaweah River system, as well as an allocation of federal stored water from Friant Dam on the San Joaquin River as part of the Friant Unit of the Central Valley Project (CVP). Surface and groundwater have been conjunctively used in this region for decades (Figure 4); however, demand for water has outstripped supply, leading to the basin being classified by the CDWR as critically overdrafted.

The water quality of the imported water supply is high, because of its low salinity given its source in the snowpack of the Sierra Nevada mountain range. Regional groundwater flow within the GKGSA is towards the southwest and the valley trough with the appearance of local groundwater cones of depression during the irrigation season [29]. A geologic feature-the Corcoran Clay aquitard-divides the upper and lower aquifers in the west of the subbasin but pinches out in the eastern half. Where present, the Corcoran Clay significantly retards flow between the upper and lower aquifers and has led to localized subsidence [29] where aquifer stresses have exceeded the pre-consolidation pressure heads 
in the lower aquifer (Figure 5). There is a more pronounced vertical flow gradient between the upper semiconfined aquifer and lower confined aquifer in those areas of the western subbasin where the Corcoran Clay is thinner or absent, resulting in higher recharge. The major groundwater quality concerns in the Kaweah subbasin are for public water supply and domestic wells and include arsenic, nitrate and certain volatile organics such as 1,2,3trichloropropane (1,2,3 TCP) associated with agriculture [29]. The contaminant risk in the lower aquifer is obviously greater where there is greater recharge.

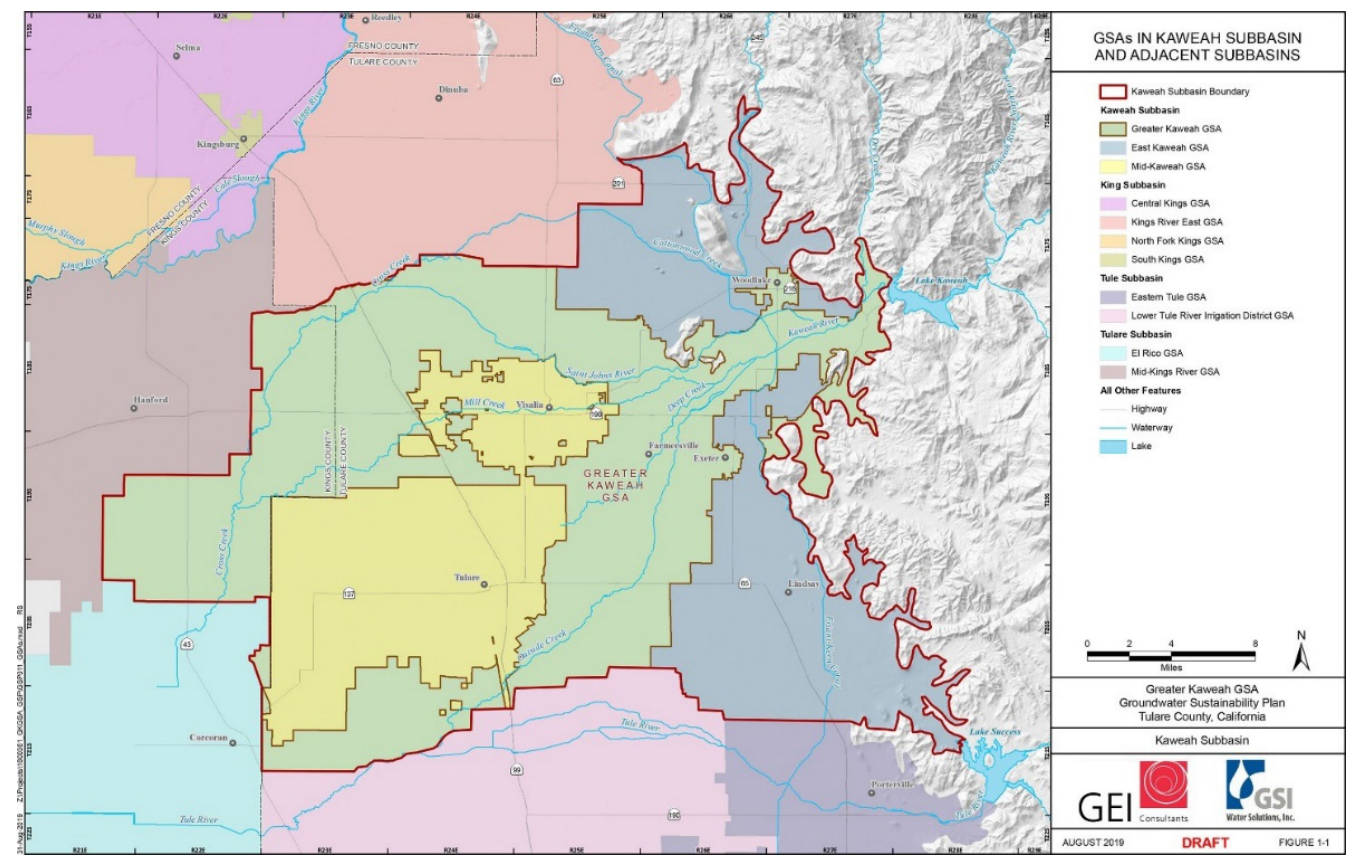

Figure 3. The Greater Kaweah Groundwater Sustainability Agency service area within the Kings River Basin showing the jurisdictional boundaries chosen by each GSA [29], https:/ /sgma.water.ca. gov/portal/gsp/preview/30 (Accessed on 1 May 2021).

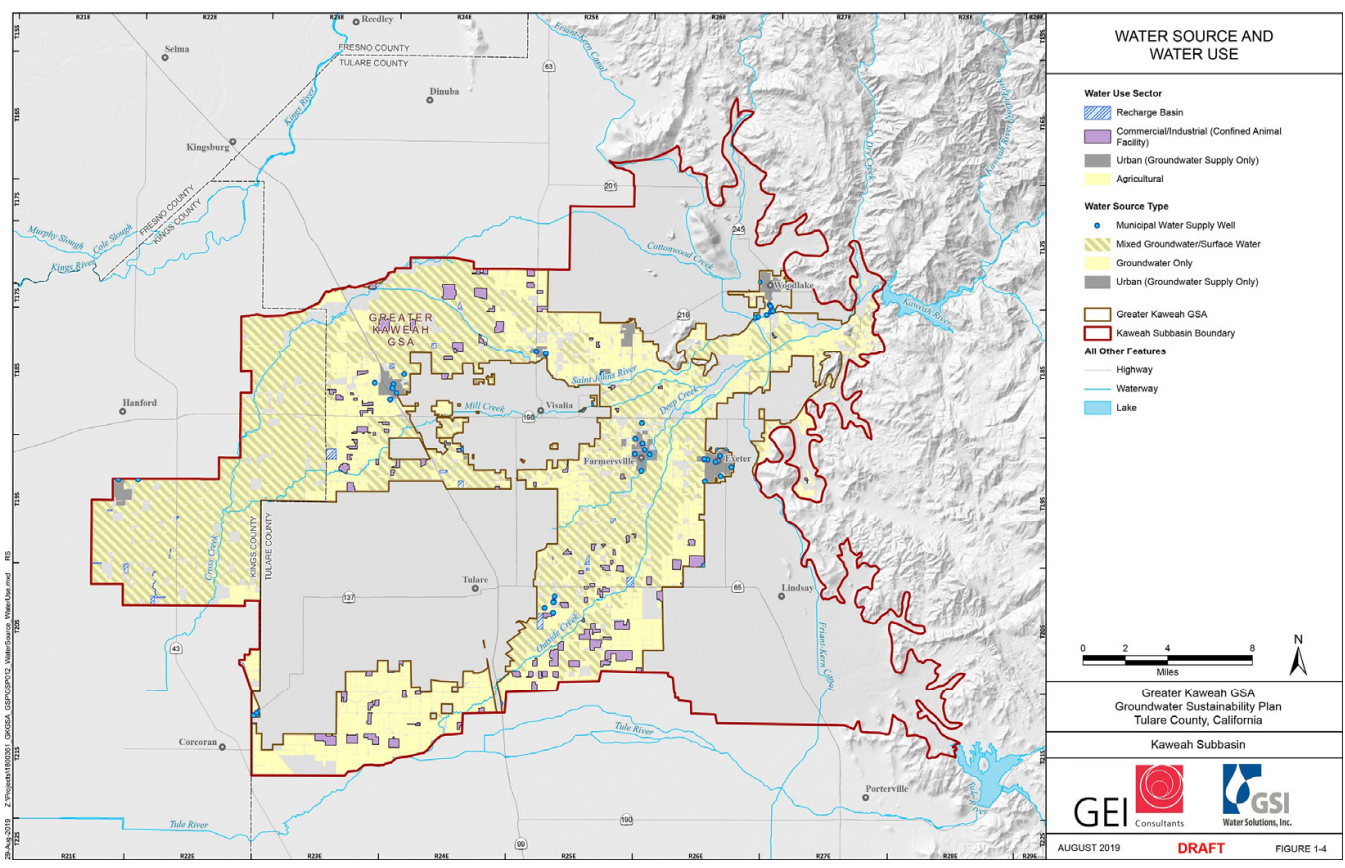

Figure 4. Water sources and water use within the GKGSA. The shaded area depicts agricultural areas served by a combination of surface and groundwater resources, whereas the yellow areas are served by groundwater alone [29], https:/ /sgma.water.ca.gov/portal/gsp/preview/30 (Accessed on 1 May 2021). 


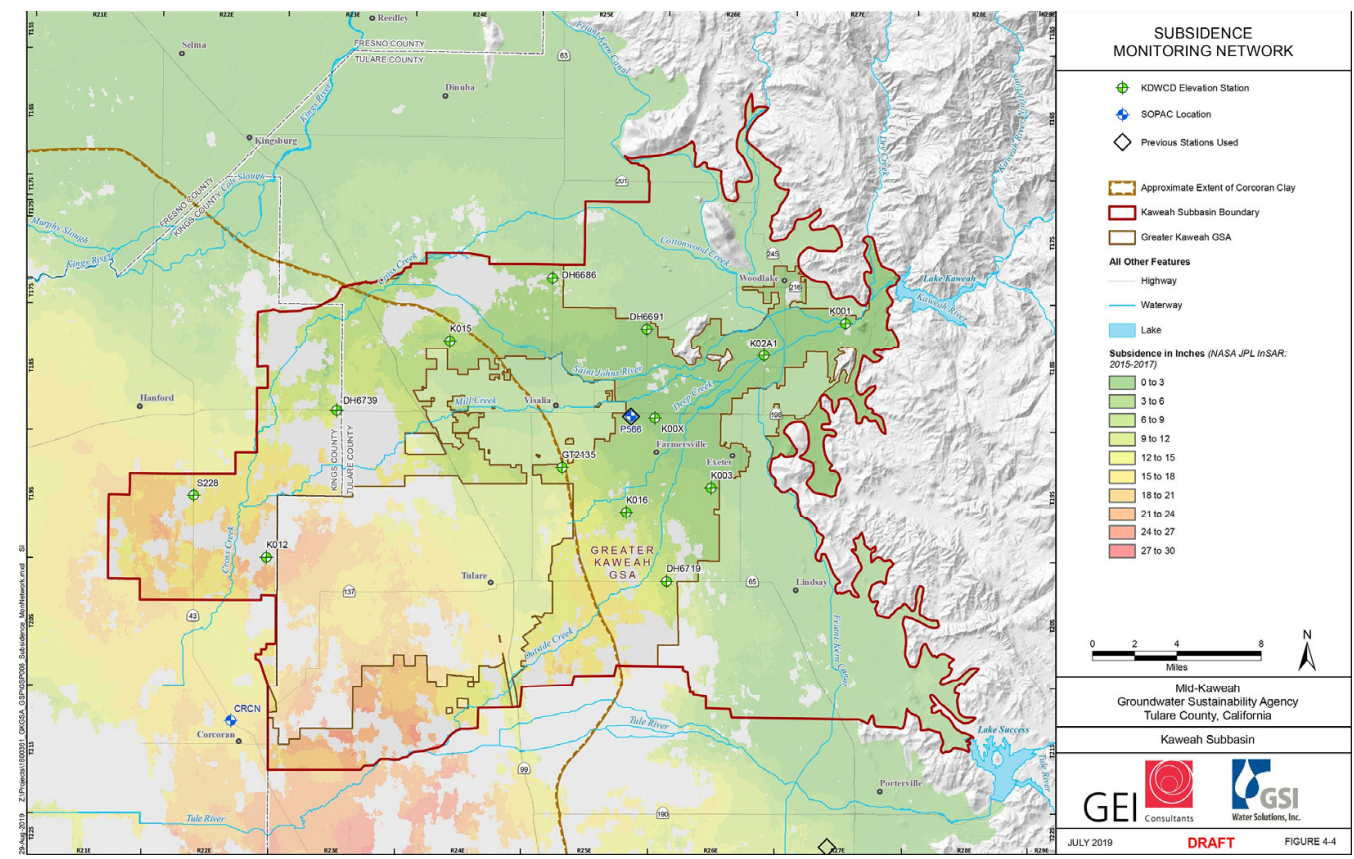

Figure 5. Active subsidence monitoring in the GKGSP service area largely in the valley trough where the influence of the Corcoran Clay aquitard on reducing lower aquifer recharge is greater [29], https:/ / sgma.water.ca.gov/portal/gsp/preview/30 (Accessed on 1 May 2021).

A review of the online documentation for the Kaweah Basin and each of the component GSAs suggests that GSA boundaries were decided largely along institutional lines, coinciding with the existing CDWR groundwater basin delineation and water district administrative boundaries. The acceptance of prior jurisdictional boundaries has provided these GSAs with considerable advantages and stakeholder support in initial planning efforts under SGMA. In the case of the GKGSA, governance has been assigned to a newly appointed nine-member Board of Directors with seats assigned to the agency itself and the original founding agencies, with various subcommittees representing stakeholders, farmers and a private water utility reporting to the board [29]. The GKGSA appears to have made a determined effort to develop a governance structure that represents diverse views and interests of individuals and entities within the GSA, including both surface water and groundwater interests. Typically, in resource planning discussions, the entities that bring the most resources to the table and that have the time to be actively engaged in the process receive the lion's share of the benefits. The GKGSA seems to have taken active steps to have solicited widespread representation.

The Board of Directors has likewise been proactive in SGMA-related conferences and meetings in entertaining ideas to improve the function of the GSA [29]. The GKGSA has also been proactive in aligning its activities with other stakeholder groups such as CVSALTS and has a committee specially designated to enhance communication with this salinity and groundwater nitrate planning effort. As previously noted, the CVSALTS salinity management effort has, hitherto, been focused on the management of surface water quality, although there is considerable overlap with SGMA water quality sustainability goals.

In general, CVSALTS has a less ambitious mandate, accomplishment goals and timeline than SGMA, although the program is similarly regional in its scope. A major regional focus in long-term plan development and implementation for long-term salt balance and in addressing current shallow well nitrate contamination issues is on disadvantaged communities. CVSALTS is conceptually aligned with SGMA GSAs in the recognition of stakeholder accepted "salinity management zones", although without the police power that is provided under SGMA. Although there has been recognition of the parallel efforts by entities such as the GKGSA, as previously noted, this has been the exception rather than the rule that 
might produce conflicting internal policy mandates among other stakeholder groups and GSAs unless addressed in the short to medium term.

\subsection{The Northern and Central Delta GSP Service Area}

The Delta Mendota subbasin is one of the most agriculturally productive and resourcevulnerable high-priority sustainability areas under SGMA in the San Joaquin Valley. The subbasin has been subdivided into six GSAs, each charged with developing their own GSPs in close coordination with the other GSAs in the subbasin. These GSP groupings include the Aliso Water District GSA, Farmers Water District GSA, Fresno County GSA, the Grassland GSA, the Northern and Central Delta-Mendota Region (NCDMR) GSA, and the San Joaquin River Exchange Contractors GSA [30] (Figure 6). The GSP service area gets its name from the fact that all areas are served by the Federal Delta Mendota Canal (DMC) that derives its water supply from a large pumping facility located in the Sacramento San Joaquin Delta. This pumping facility is subject to environmental restrictions related to the anadromous salmon fishery and vulnerable protected fish species such as the delta smelt that can curtail allowable pumping rates.

The term "regulatory drought" has been used to describe restrictions in water supply imported from the delta that can occur even during normal and wet years where water supply reservoirs have sufficient available storage. This imported water supply contains salts, although at concentrations low enough to have any effect on agricultural crop yields. Agricultural return flows and subsurface drainage often contain elevated salinity concentrations that can impact crop yields if applied directly. The salinity impairment of the San Joaquin River is largely the result of federal water development initiatives in the 1960s that permanently impacted the sustainability of the western San Joaquin River Basin [30].

The NCDMR GSA [30] is the most diverse of the six GSAs within the GSP service area and is the GSA that will likely experience the greatest adjustments to current practices to meet SGMA long-term objectives over the next 20 years. This GSA and the other GSAs in the subbasin combine component organization and administrative structures and legal authorities following the semi-distributed model described earlier. This compromise has melded together entities that have resources and groundwater management challenges in common. For example, the three largest entities the Grassland GSA, the NCDMR GSA, and the San Joaquin River Exchange Contractors GSA have uniquely recognized rights to irrigation water supply that have a direct effect on annual aquifer recharge. Grassland Water District (private) and the adjacent state and federal wildlife refuges receive direct and incremental (when available) water supply to maintain seasonally managed wetlands from the USBR under a legislative mandate to sustain overwintering waterfowl habitats on the Pacific flyway [9]. The San Joaquin River Exchange Contractors GSA holds senior, pre-1914, water rights on the San Joaquin River on account of their trade of San Joaquin River diversions for water pumped south from the Sacramento San Joaquin Delta [31]. This "exchange contract" for water supply, enacted in 1939, typically provides this region with adequate supply to meet most crop demands, although, with a shift in land use and the cultivation of orchards and other permanent crops over the past decade, some areas are overdrafted and have experienced significant groundwater pumping-induced land subsidence [31].

The NCDM GSA is supplied largely by DMC surface water deliveries, groundwater pumpage and drainage reuse in the southern sector of the subarea and by a combination of surface water deliveries, groundwater pumpage and diversions from the San Joaquin River in the northern sector (Figure 7). Due to this significant difference in water resource availability, aquifer sustainability issues are less severe in the northern sector, with no reported instances of land subsidence. 


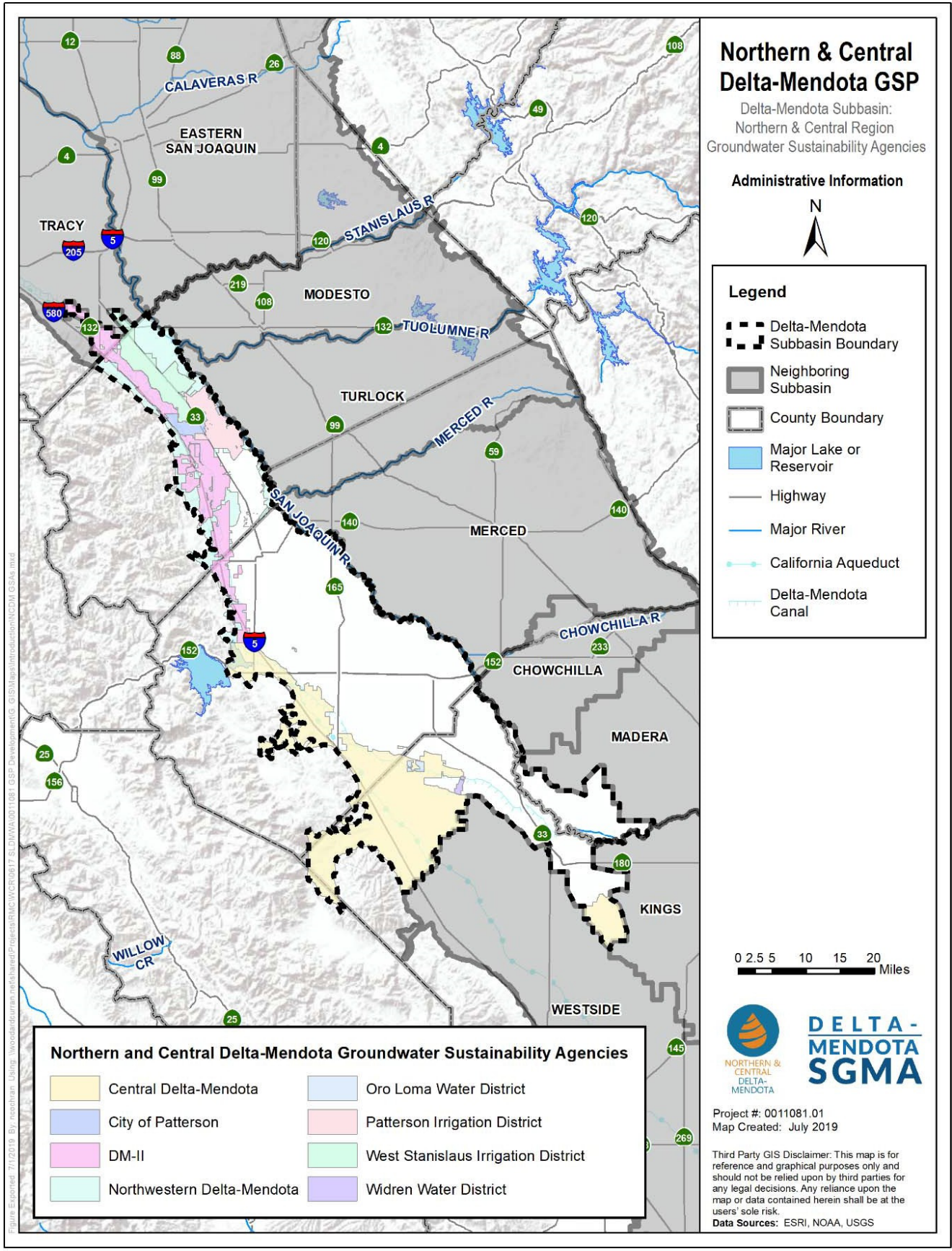

Figure 6. The Delta Mendota subbasin showing the boundary of the Northern and Central Delta Mendota GSA and GSP planning areas [30]. The Delta Mendota SGMA planning areas recognize sub-regional differences in water resource availability including access to federal water supply and the San Joaquin River. Water supply contracts follow both riparian and appropriative contract law priorities based on water rights, https:/ /sgma.water.ca.gov/portal/gsp/preview/13 (Accessed on 1 May 2021). 


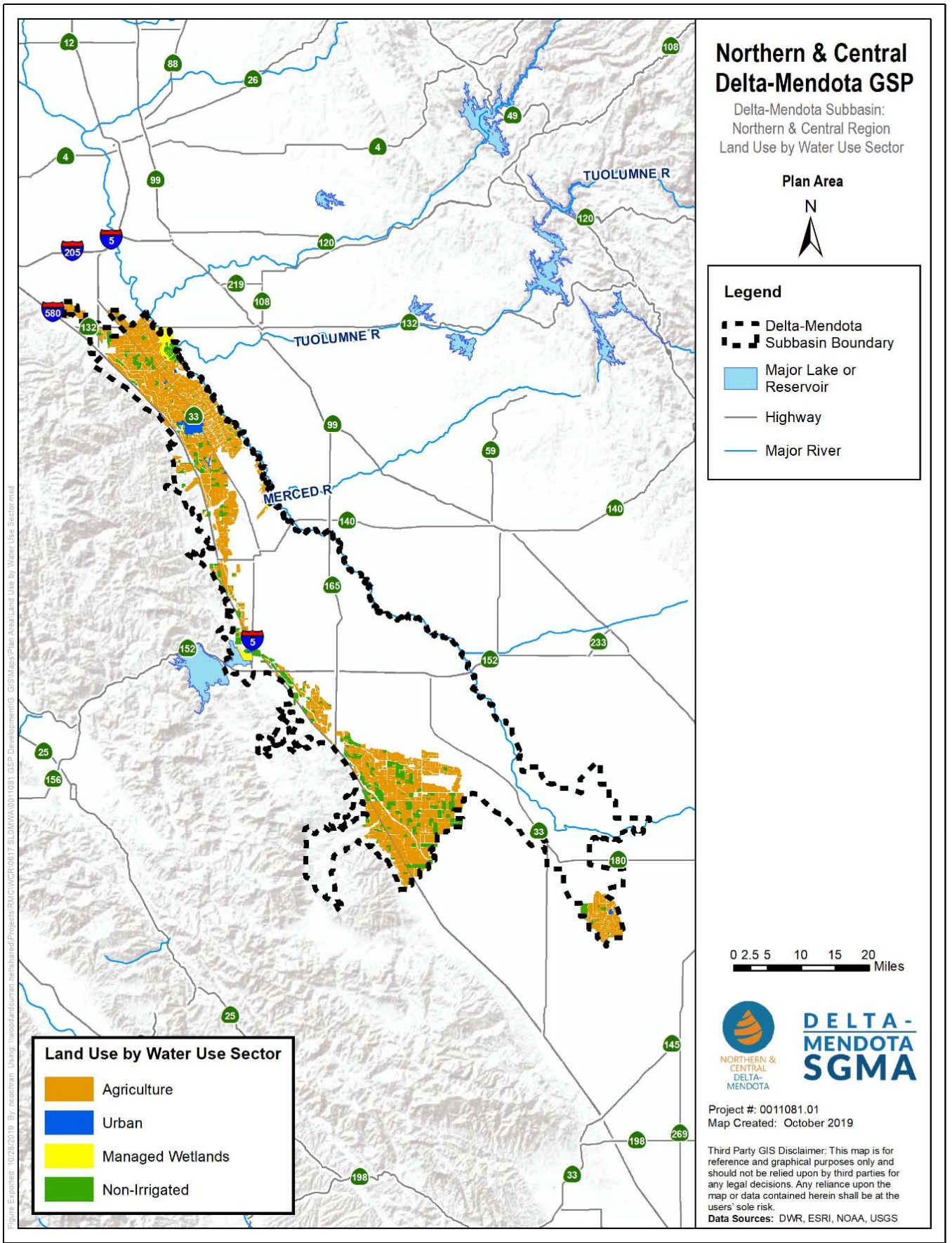

Figure 7. Land ownership in the Delta Mendota subbasin showing the boundary of the Northern and Central Delta Mendota GSA and GSP planning area [30]. Agricultural land use has changed in favor of permanent crops such as orchards and vines over the past 20 years which has reduced water resource resiliency. Managed seasonal wetlands and urban land uses are dominant in other GSAs within the Delta-Mendota Subbasin boundary, https://sgma.water.ca.gov/portal/gsp/preview/13 (Accessed on 1 May 2021).

The San Luis and Delta Mendota Water Authority (SLDMWA) is a USBR contractor that is responsible for the operation and maintenance of the Delta Mendota Canal and other federally owned conveyances throughout the Delta Mendota subbasin and is the logical entity to provide liaison with stakeholders to manage the coordination of groundwater resources in the basin. This responsibility is outside the SLDMWA's normal portfolio and has required the development and acquisition of expertise in hydrogeology and 
modeling that hitherto has not been essential for the SLDMWA operation. Data acquisition and assimilation activities such as the monitoring of canal deliveries and the structural integrity of the canal have been supplemented with active monitoring of land subsidence in the vicinity of the water distribution canals and other infrastructure. Differential land subsidence can cause significant structural damage to the canal lining that is very costly to repair as well as diminishing the volume of water that can be conveyed along the canal as canal flow gradients are reduced. Land subsidence monitoring is concentrated on the western fringe of the GSA (Figure 8) where water supply allocation has, historically, been lower and soils are coarser grained-retaining less moisture in the crop rootzone.

Agricultural landowners expect the SLDMWA to identify projects and management actions for implementation over time that reduce reliance on the groundwater resource and entrust the authority to be a neutral facilitator in the development of equitable and cost-effective water resource management strategies. Communiques to date suggest that no internal regulatory actions affecting subbasin GSAs are expected during the first five years of the twenty-year GSP implementation glide path. Initial efforts will address informational and data gaps and reconcile the results provided by preliminary water balance models with more rigorous regional numerical models of the subbasin. The strategy undertaken appears to have begun with the lowest common denominator analytical tool to bring all stakeholders on board and then introduce more highly discretized and rigorous numerical modeling tools once a basic level of acceptance has been achieved and a level of trust has been achieved between neighboring GSAs.

The stakeholder engagement strategy adopted has sought to provide a forum to solicit and discuss the interests of all beneficial users of groundwater in the subbasin [30]. To this end, a website was created where all meeting and public workshop materials, as well as supplemental resources, are posted regularly in addition to more typical information distribution to property owners and other stakeholders. Committees have been formed to include representatives from water and irrigation districts representing large and small landowners as well as municipal water providers with the aim of representing the diverse social, cultural, and economic characteristics of the subbasin population. Despite this progress, the current status and activity level on the web portal suggests that this endeavor has not been wholly successful and that latent resource competition among stakeholders both within and between GSAs has made it difficult to fully recognize and protect minority stakeholder interests. This is contrast to the GSA cooperation and stakeholder outreach in the Kaweah subbasin, where a less diverse stakeholder community has made accommodations easier.

It is generally recognized within the GSP service area that major curtailment in groundwater pumping will need to occur to sustain agriculture. This curtailment will not be uniformly spread across the GSP service area and the brunt will most likely be felt by the NCDM GSA that generally has the most junior water rights in the basin and where subregional irrigation recharge is lowest. Although the GSP service area appears to be in a holding pattern at the present time during severe drought conditions that will likely stall groundwater pumping curtailment, a number of startup companies such as AquaOSO Technologies PBC, specializing in decision support to stakeholders and agricultural lenders, have become active [32]. It follows that as available water supply becomes more restricted due to drought and SGMA-mandated reductions in allowable groundwater extraction, that the risk to agricultural financial institutions and investors in crop land becomes more acute [33]. The marketplace generally deals with this increased risk by deflating the value of land and farming enterprises to a point where the reduction in value offsets the higher financial risk [32,33]. These new entities will likely become a catalyst for future anticipated change in future land use and agricultural investment outcomes. 


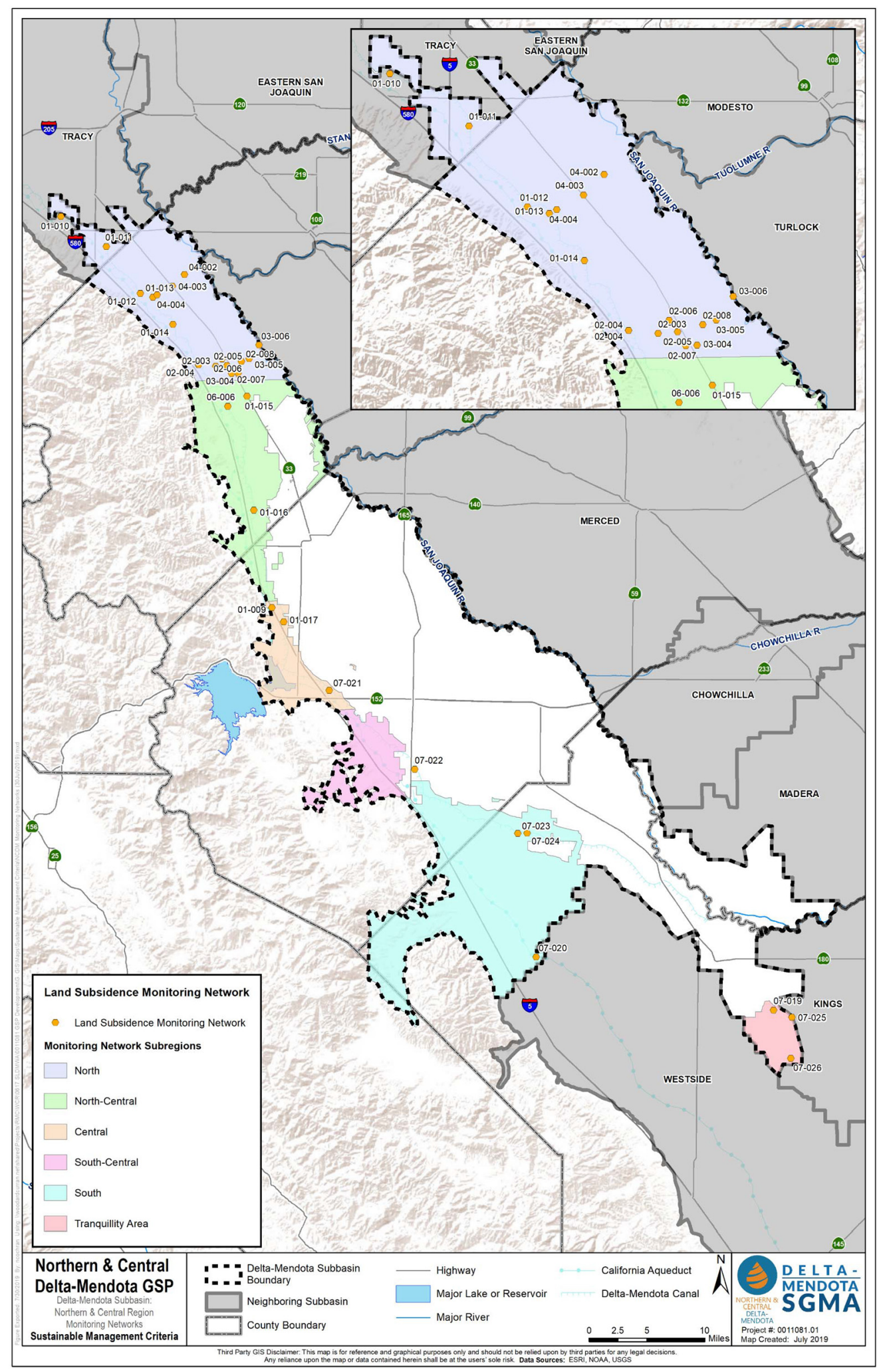

Figure 8. Areas of active land subsidence monitoring where excess groundwater withdrawal has caused differential subsidence and damage to some water conveyance facilities [30]. Most active subsidence occurs along the western sector of the Delta Mendota subbasin. Subsidence monitoring is conducted by multiple agencies and includes individual extensometer and GPS station monitoring and airborne INSAR (interferometric radar) surveys, https:/ /sgma.water.ca.gov/portal/gsp/preview /13 (Accessed on 1 May 2021). 


\section{Summary and Conclusions}

The innovative nature of the SGMA and the CVSALTS initiatives both underway in California to address serious resource management issues of groundwater over-pumping and impairment of river water quality has elevated the state to be recognized among the most progressive resource managers in the nation. The emphasis and empowerment of stakeholders in these largely stakeholder-led initiatives has been guided by current research in the social sciences that has shown that bottom-up approaches can work and be effective if supported by state-of-the-art technologies including real-time sensor networks, airborne and satellite remote sensing surveys, Geographic Information Systems for enhanced data visualization and the use of appropriate simulation models for advanced decision support. These tools provide a springboard for stakeholder innovation and compromise that will be essential elements of long-term, equitable and robust sustainable solutions. In the course of implementing these two initiatives, many weaknesses in the support system were revealed, largely around data availability, data sharing and data quality assurance. Flaws also were revealed in the ability of sophisticated numerical models to adequately estimate current levels of groundwater pumping as a residual between water requirements and water supply and in the impacts of this pumping for the water quality of surface and groundwater and land subsidence. These findings have stimulated further innovation, especially in the recognition of better decision support tools and web-based data portals to facilitate safe data sharing and cooperation among impacted stakeholders. The case study of two very different GSP development efforts-one on the west side of the San Joaquin Valley in the north-west side and Grasslands subbasins and the other mostly on the east side of the Kings River Basin-contrasts the resource management issues and the approaches being taken to develop stakeholder consensus and empower decision making. The early successes and high public visibility of efforts underway within the GKGSA suggest that strong local leadership, advocacy and an emphasis on coordination can play a significant role in achieving long-term goals for both the SGMA and CVSALTS initiatives.

Author Contributions: N.W.T.Q. and J.D.O. authored the manuscript. First draft prepared by N.W.T.Q. Both authors have read and agreed to the published version of the submitted manuscript.

Funding: This research received no external funding.

Institutional Review Board Statement: Not applicable.

Informed Consent Statement: Not applicable.

Data Availability Statement: Not applicable.

Acknowledgments: The authors are also grateful to Daniel Nelson, past Executive Director of the San Luis and Delta Mendota Water Authority, for his invaluable comments and suggestions as a stakeholder reviewer of the manuscrip. The authors are also appreciative of the work of the California Water and Environmental Modeling Forum for holding SGMA-related sessions at annual meetings since 2018.

Conflicts of Interest: The authors declare no conflict of interest.

\section{References}

1. State of California. 2014. The Sustainable Groundwater Management Act. Available online: http://leginfo.legislature.ca.gov/ faces / codes_displayexpandedbranch.xhtml?tocCode=WAT\&division=6.\&title=\&part=2.74.\&chapter=\&article $($ accessed on 16 December 2020).

2. CVSALTS. Salt Control Program. 2021. Available online: https://www.cvsalinity.org/salt-control-program (accessed on 20 May 2021).

3. California Department of Water Resources. California's Groundwater (Bulletin 118). 2020. Available online: https:/ water.ca. gov/Programs/Groundwater-Management/Bulletin-118 (accessed on 16 December 2020).

4. Thompson, B.; Rohde, M.M.; Howard, J.K.; Matsumoto, S.; Mind the Gaps: The Case for Truly Comprehensive Sustainable Groundwater Management. Water in the West. Stanford Digital Repository. 2021. Available online: https://purl.stanford.edu/ hs475mt1364 (accessed on 1 May 2021). 
5. California Department of Water Resources. Best Management Practices for the Sustainable Management of Groundwater: Hydrogeologic Conceptual Model 2016. Available online: https://water.ca.gov/-/media/DWR-Website/Web-Pages/ Programs/Groundwater-Management/Sustainable-Groundwater-Management/Best-Management-Practices-and-GuidanceDocuments/Files/BMP-3-Hydrogeologic-Conceptual-Model_ay_19.pdf (accessed on 7 January 2021).

6. Oster, J.D.; Wichelns, D.E.W. Hilgard and the history of irrigation in the San Joaquin Valley: Stunning productivity, slowly undone by inadequate drainage. In Salinity and Drainage in San Joaquin Valley, California: Science, Technology, and Policy; Chang, A.C., Silva, D.B., Eds.; Springer: Dordrecht, The Netherlands, 2014; pp. 7-46.

7. Larson, K.J.; Basagaoglu, H.; Marion, M.A. Prediction of optimal safe ground water yield and land subsidence in the LosBanosKettleman City area, California, using a calibrated numerical simulation model. J. Hydrol. 2001, 242, 79-102. [CrossRef]

8. CALFED Bay-Delta Program. Programmatic Record of Decision; Sacramento, CA, USA, 2000; Volume 1, p. 1. Available online: https:/ / www.ccwater.com/DocumentCenter/View/3213/CALFED-Programmatic-ROD--Aug-28-2000?bidId= (accessed on 5 May 2021).

9. Quinn, N.W.T. The San Joaquin Valley: Salinity and Drainage Problems and the Framework for a Response. In Salinity and Drainage in San Joaquin Valley, California: Science, Technology, and Policy, Global Issues in Water Policy 5; LBNL Topical Report-LBL-38498; Chang, A.C., Brawer Silva, D., Eds.; Springer: Dordrecht, The Netherlands, 2014. [CrossRef]

10. Quinn, N.W.T. Policy Innovation and Governance for Irrigation Sustainability in the Arid, Saline San Joaquin River Basin. Sustainability 2020, 12, 4733. [CrossRef]

11. California Department of Water Resources. California Data Exchange Center. Historical Sacramento and San Joaquin Valley Water Year Index. Available online: http:/ / cdec.water.ca.gov/cgiprogs/iodir/WSIHIST (accessed on 1 May 2021).

12. Leahy, T.C. Desperate Times Call for Sensible Measures: The Making of the California Sustainable Groundwater Management Act. Golden Gate Univ. Environ. Law J. 2015, 9, 4. Available online: http://digitalcommons.law.ggu.edu/gguelj/vol9/iss1/4 (accessed on 5 May 2021).

13. Chappelle, C.; Hanak, E.; Harter, T. Groundwater in California. Public Policy Institute of California: San Francisco, California. 2017. Available online: https:/ /www.ppic.org/publication/groundwater-in-california/ (accessed on 16 December 2020).

14. California Department of Water Resources. Drought Information. Available online: https://water.ca.gov/Current-Conditions (accessed on 10 June 2021).

15. Little Hoover Commission. Still Imperiled, Still Important. The Little Hoover Commission's Review of the CALFED BayDelta Program. Governor Arnold Schwarzenegger. “Governor's Reorganization Plan 1: Reforming California's Boards and Commissions." Little Hoover Commission Public Hearing on Reorganization Plan 1. 26 January 2005. Available online: https://lhc.ca.gov/report/search?search_api_views_fulltext=calfed+bay+delta (accessed on 10 June 2021).

16. California Department of Water Resources. California's Groundwater Update 2020 (Draft). 2020. Available online: https: / / water.ca.gov / Programs/GroundwaterManagement/Bulletin-118 (accessed on 17 March 2021).

17. California Department of Water Resources. Basin Prioritization. 2019. Available online: https://water.ca.gov/Programs/ Groundwater-Management/Basin-Prioritization (accessed on 7 January 2021).

18. Dunning, H.C. The Governor's Commission: Success or Failure. 2005. Available online: https://heinonline.org/HOL/Page? handle=hein.journals $/ \mathrm{mcglr} 36 \&$ div=13\&g_sent=1\&casa_token=\&collection=journals (accessed on 5 March 2021).

19. Osterling, E. 2020. Available online: https://groundwaterexchange.org/aiovg_videos/gsa-101-understanding-the-sustainablegroundwater-management-act/ (accessed on 10 June 2021).

20. Dogrul, E.C.; Brush, C.F.; Kadir, T.N. Integrated Water Flow Model (IWFM), a Tool for Numerically Simulating Linked Groundwater, Surface Water and Land-Surface Hydrologic Processes; California Department of Water Resources: Sacramento, CA, USA, 2011.

21. Brush, C.F.; Dogrul, E.C.; Kadir, T.N.; Chung, F.I. Applying C2VSIM, an Integrated Hydrologic Model of California's Central Valley, to Assess Local and Regional Impacts of Conjunctive Use Projects; California Department of Water Resources: Sacramento, CA, USA, 2011.

22. Ritchie, S.R.; Acting Executive Director; CALFED Bay-Delta Program. "Memo to Policy Group Regarding Long-Term Governance." CALFED Bay-Delta Program: February 25; CALFED Bay-Delta Program: Sacramento, CA, USA, 2000.

23. Kiparsky, M.; Owen, D.; Nylen, N.G. Designing Effective Groundwater Sustainability Agencies: Criteria for Evaluation of Local Governance Options; UC Berkeley Center for Law, Energy \& the Environment: Berkeley, CA, USA, 2016; Available online: http:/ / bit.ly/2236VHC (accessed on 22 March 2021).

24. US Bureau of Reclamation. California Bay-Delta Public Advisory Committee Charter; US Department of the Interior: Washington, DC, USA, 2001.

25. Faunt, C.C.; Hanson, R.T.; Belitz, K. Introduction, Overview of Hydrogeology, and Textural Model of California's Central Valley. In Groundwater Availability of the Central Valley Aquifer, California; U.S. Geological Survey Professional Paper 1766; Faunt, C.C., Ed.; U.S. Geological Survey: Reston, VA, USA, 2009; pp. 1-54.

26. Faunt, C.C.; Belitz, K.; Hanson, R.T. Groundwater Availability in California's Central Valley. In Groundwater Availability of the Central Valley Aquifer, California; U.S. Geological Survey Professional Paper 1766; Faunt, C.C., Ed.; U.S. Geological Survey: Reston, VA, USA, 2009; pp. 59-116.

27. Faunt, C.C.; Hanson, R.T.; Belitz, K.; Schmid, W.; Predmore, S.P.; Rewis, D.L.; McPherson, K. Numerical Model of the Hydrologic Landscape and Groundwater Flow in California's Central Valley. In Groundwater Availability of the Central Valley Aquifer, California; U.S. Geological Survey Professional Paper 1766; Faunt, C.C., Ed.; U.S. Geological Survey: Reston, VA, USA, 2009 ; pp. $121-207$. 
28. Neely, W.R.; Borsa, A.A.; Burney, J.A.; Levy, M.C.; Silverii, F.; Sneed, M. Characterization of groundwater recharge and flow in California's San Joaquin Valley from InSAR-observed surface deformation. Water Resour. Res. 2021, 57. [CrossRef] [PubMed]

29. Greater Kaweah Groundwater Sustainability Agency. Groundwater Sustainability Plan (GSP)—Final. Prepared under the Kaweah Subbasin Coordination Agreement with Mid-Kaweah GSA and East Kaweah GSA. 22 January 2020. Available online: https://sgma.water.ca.gov/portal/gsp/preview/30 (accessed on 8 May 2021).

30. Northern and Central Delta Mendota. 2019. Groundwater Sustainability Plan (GSP). For the Northern and Central Delta-Mendota Regions. November 2019. Available online: https://sgma.water.ca.gov/portal/gsp/preview/13 (accessed on 8 May 2021).

31. Arax, M.; Wartzman, R. The King of California: J.G. Boswell and the Making of A Secret American Empire; PublicAffairs: New York, NY, USA, 2005; ISBN 1-58648-281-5.

32. AquaOSO Technologies PBC. Water Security in the Age of SGMA. Downloadable E-Book. Available online: https://aquaoso. com/resources/white-papers-ebooks/ (accessed on 18 May 2021).

33. AquaOSO Technologies PBC. Lending a Hand to California Agriculture. Downloadable E-Book. Available online: https: //aquaoso.com/resources/white-papers-ebooks/ (accessed on 18 May 2021). 